Original Research Article

\title{
Relation between hyponatremia and alteration in gross metabolic parameters after atypical antipsychotic therapy
}

\author{
K. K. Daryani ${ }^{1}$, Gargi Sethi ${ }^{1 *}$, Shivank Sethi ${ }^{2}$
}

\begin{abstract}
${ }^{1}$ Department of Pharmacology,
${ }^{2}$ Student, Netaji Subhash Chandra Bose Medical College, Jabalpur, Madhya Pradesh, India
\end{abstract}

Received: 30 March 2019 Accepted: 19 April 2019

\section{*Correspondence to:}

Dr. Gargi Sethi,

Email: garginscb@gmail.com

Copyright: (C) the author(s), publisher and licensee Medip Academy. This is an openaccess article distributed under the terms of the Creative Commons Attribution NonCommercial License, which permits unrestricted noncommercial use, distribution, and reproduction in any medium, provided the original work is properly cited.

\begin{abstract}
Background: Weight gain and hyponatremia which is dilutional in nature, has been well known adverse effects associated with use of atypical antipsychotic medication but the plausible impact of dilutional hyponatremia on weight gain has not been explored.

Methods: One hundred and three patients more than 18 years of age of either gender who were prescribed, olanzapine or risperidone, were tested for serum electrolytes $\left(\mathrm{Na}^{+}\right.$and $\left.\mathrm{K}^{+}\right)$and gross metabolic parameters (weight and waist circumference) were measured for baseline and post drug testing.

Results: Most common age group was 30-39 years of age in the patient study sample $(n=103)$ with $38(36.90 \%)$ patients were females while rest $63(63.10 \%)$ were males. There was no significant association between serum sodium levels and weight gain was observed ( $p>0.05$ ). It was observed that in olanzapine group $64 \%$ of the studied cases had weight gain whereas in risperidone group only $20.8 \%$ reported weight gain $(\mathrm{p}<0.001)$. There was significant association between olanzapine and increase in waist circumference over risperidone, irrespective to serum sodium status $\left(\mathrm{x}^{2}=0.0148, \mathrm{p}>0.05\right)$.

Conclusions: Olanzapine was primarily responsible for weight gain and increase in waist circumference over risperidone. These gross metabolic parameters were not influenced by hyponatremia.
\end{abstract}

Keywords: Atypical antipsychotic, Hyponatremia, Weight gain, Waist circumference

\section{INTRODUCTION}

The global burden of disease (GBD) studies have derived detailed and comparable epidemiological and burden of disease estimates for all countries and concluded that although schizophrenia is a low prevalence disorder, the burden of the disease is substantial. Globally, prevalent cases rose from 13.1 (95\% UI: 11.6-14.8) million in 1990 to 20.9 (95\% UI: 18.5-23.4) million cases in 2016. Schizophrenia contributes 13.4 (95\% UI: 9.9-16.7) million years of life lived with disability to burden of disease globally. ${ }^{1}$ Atypical antipsychotic drugs are the cornerstone of therapy and are routinely prescribed for the treatment of these psychiatric disorders such as schizophrenia, acute psychosis, schizophreniform psychosis, delusional disorder as well as for behavioural and psychological symptoms of dementia. Commonly used atypical antipsychotics include risperidone, olanzapine and quetiapine. . $^{2,-9}$

Weight gain can lead to hypertension, coronary heart disease and diabetes mellitus and also have psychological 
consequences like low self-esteem and impaired social functioning. ${ }^{10}$ Drug-induced weight gain has long been recognized, particularly as a consequence of the use of psychotropic medication. ${ }^{11,12}$ More recently, some newer atypical antipsychotics have also been firmly associated with weight gain. ${ }^{13}$ Although weight gain has been a documented adverse effect of antipsychotic drugs for decades, it has received surprisingly little attention. ${ }^{14}$

Numerous case reports have suggested a possible association between atypical antipsychotics and hyponatremia but is limited to only a few studies. Only one case control study has examined the association between atypical antipsychotic use and hyponatremia. ${ }^{15}$

Atypical antipsychotic drugs have become the most widely used agents because of their superiority with regard to safety and tolerability profile compared to conventional typical antipsychotics. ${ }^{16}$

The present study intended to evaluate the association between use of atypical antipsychotic medications and gross metabolic derangements if any, by taking into account hyponatremia and two parameters namely weight gain and increase in waist circumference as a part of metabolic monitoring.

\section{METHODS}

This prospective observational study was carried out after obtaining due approval from the institutional ethics committee at Department of Pharmacology in collaboration with the Department of Psychiatry, Netaji Subhash Chandra Bose Medical College and Hospital, Jabalpur, Madhya Pradesh, India from March 2017 to March 2018.

One hundred and three patients of more than 18 years of age and either gender who presented to the psychiatry clinics and were prescribed, olanzapine or risperidone by the consultant psychiatrist were included after obtaining informed consent. Exclusion criteria were patient refusal, patients on more than one antipsychotic drugs, pregnancy, hypothyroidism, diabetes mellitus, hypovolemia, edema, ascites, patients receiving any other medication likely to affect the parameters being observed, alcoholism, any other addiction.

Detailed history was obtained, and a thorough physical examination was done. Blood sample for estimation of serum electrolytes $\left(\mathrm{Na}^{+}\right.$and $\left.\mathrm{K}^{+}\right)$was drawn and sent for testing to the pathology laboratory, weight and waist circumference were measured at baseline and two weeks after drug administration.

The patient and the accompanying attendant were counselled regarding compliance with the medication regimen. The data of the present study was recorded and analysed with the help of SPSS 20 software for windows. Appropriate univariate and bivariate analysis using paired t-test was applied to check the hypothesis. All means were expressed as mean \pm standard deviation and proportion was expressed as percentage. The critical value for the significance of the results was considered at 0.05 level.

\section{RESULTS}

Most common age group was 30-39 years of age in the patient study sample $(n=103)$ with observed mean of $35.04 \pm 11.539$ (Mean \pm SD) years. Thirty eight patients $(36.90 \%)$ were females while rest 63 patients $(63.10 \%)$ were males.

In the present study, a higher proportion of patients $(64.10 \%)$ were clinically diagnosed as schizophrenics, $33 \%$ were having schizoaffective disorder and $2.9 \%$ had a brief psychotic disorder.

In cases with a serum sodium level less than or equal to 139 $\mathrm{mmol} / \mathrm{l}, 8$ cases $(36.4 \%)$ were observed to have gained weight and 14 cases $(63.6 \%)$ did not show any change in weight. In cases with serum sodium level more than 139 $\mathrm{mmol} / \mathrm{L}$, the proportion of cases that gained weight was 35 $(43.2 \%)$. Statistically no significant association between serum sodium levels and weight gain was observed ( $p$ $>0.05$ ) (Table 1).

Table 1: Association between weight gain and serum sodium level aftertreatment with atypical antipsychotic medications.

\begin{tabular}{|c|c|c|c|}
\hline \multirow{2}{*}{ Weight gain } & \multicolumn{2}{|c|}{ Serum sodium mmol/l } & \multirow{2}{*}{ Total } \\
\hline & $\leq 139$ & $>139$ & \\
\hline \multirow{2}{*}{ No } & 14 & 46 & 60 \\
\hline & $63.60 \%$ & $56.80 \%$ & $58.30 \%$ \\
\hline \multirow{2}{*}{ Yes } & 8 & 35 & 43 \\
\hline & $36.40 \%$ & $43.20 \%$ & $41.70 \%$ \\
\hline \multirow{2}{*}{ Total } & 22 & 81 & 103 \\
\hline & $100.00 \%$ & $100.00 \%$ & $100.00 \%$ \\
\hline
\end{tabular}

It was observed that in olanzapine group $64 \%$ of the studied cases had weight gain whereas in risperidone group only $20.8 \%$ reported weight gain. Statistically this was significant ( $p$ <0.001). Thus, it was observed that olanzapine has a higher probability to cause weight gain as compared to risperidone (Table 2).

Table 2: Association between weight gain and treatment with an atypical antipsychotic medication (olanzapine or risperidone).

\begin{tabular}{|lll|l|}
\hline Weight gain & Olanzapine & Risperidone & Total \\
\hline \multirow{2}{*}{ Yes } & 32 & 11 & 43 \\
\hline \multirow{2}{*}{ No } & $64.0 \%$ & $20.8 \%$ & $41.7 \%$ \\
\hline Total & 18 & 42 & 60 \\
\cline { 2 - 4 } & $36.0 \%$ & $79.2 \%$ & $58.3 \%$ \\
\hline
\end{tabular}

$\mathrm{x} 2=19.785 ; \mathrm{p}<0.001$. 
The Table 3 shows, in less than or equal to 139 serum sodium level categories, olanzapine was given in 8 cases, of which $75 \%$ were observed with increase in waist circumference whereas a total of 14 cases received risperidone, of which only $28.6 \%$ reported increase in waist circumference. Statistically this showed significant association between olanzapine and increase in waist circumference $\left(x^{2}=4.43, p<0.05\right)$. Similarly, in more than 139 serum sodium level categories, olanzapine was given in 42 cases, of which $73.8 \%$ were observed with increase in waist circumference whereas a total of 39 cases received risperidone, of which only $17.9 \%$ reported increase in waist circumference. Statistically this too showed significant association between olanzapine and increase in waist circumference $\left(x^{2}=25.34, \mathrm{p}<0.05\right)$. The results revealed that olanzapine was primarily responsible for increase in waist circumference over risperidone while there was no impact of sodium status on the same $\left(x^{2}=0.0148, p>0.05\right)$.

Table 3: Association between increase in waist circumference, serum sodium level and treatment with an atypical antipsychotic medication (olanzapine or risperidone).

\begin{tabular}{|c|c|c|c|c|}
\hline \multirow{2}{*}{ Increase in waist circumference } & \multicolumn{2}{|c|}{ Serum sodium $\leq 139 \mathrm{mmol} / \mathrm{L}$} & \multicolumn{2}{|c|}{ Serum sodium $>139 \mathrm{mmol} / \mathrm{L}$} \\
\hline & Olanzapine & Risperidone & Olanzapine & Risperidone \\
\hline \multirow{2}{*}{ Yes } & 6 & 4 & 31 & 7 \\
\hline & $75.0 \%$ & $28.6 \%$ & $73.8 \%$ & $17.9 \%$ \\
\hline \multirow{2}{*}{ No } & 2 & 10 & 11 & 32 \\
\hline & $25.0 \%$ & $71.4 \%$ & $26.2 \%$ & $82.1 \%$ \\
\hline \multirow[t]{2}{*}{ Total } & 8 & 14 & 42 & 39 \\
\hline & \multicolumn{2}{|c|}{$x^{2}=4.43, \mathrm{p}<0.05$} & \multicolumn{2}{|c|}{$x^{2}=25.34, \mathrm{p}<0.05$} \\
\hline
\end{tabular}

\section{DISCUSSION}

A total of 103 patients were included in this prospective before-after observational study.

The observed mean age of the patient sample in the present study was 35.04 years $( \pm 11.539)$, which is somewhat similar to the mean age of the patients in the study by Meulendijks D et al. ${ }^{4}$ The mean age of patients in the study by Mannesse CK et al, was 66.5 years $( \pm 18.5)$ and that of the patients in the study by Gandhi $\mathrm{S}$ et al, was 81 years $( \pm 7.7))^{2,15}$

In the present study, gender distribution was (63.1\%) males which is somewhat similar to the study by Meulendijks D et al, which had (57\%) males, by Mannesse CK et al, had $66.5 \%$ and Gandhi $\mathrm{S}$ et al, had $67 \%$ males. $^{2,4,15}$

Fifty patients $(48.5 \%)$ received atypical antipsychotic medication olanzapine and 53 patients $(51.50 \%)$ received atypical antipsychotic medication risperidone.

Although hyponatremia is usually defined as serum sodium levels less than $136 \mathrm{mmol} / \mathrm{l}$, a more conservative definition of hyponatremia (sodium levels <138 mmol/l) was suggested by Kumar $\mathrm{S}$ et al. ${ }^{17}$ When considering a serum sodium level in the range $\leq 138 \mathrm{mmol} / 1$, the incidence of hyponatremia in the present study was $16.5 \%$ before treatment, which after treatment with atypical antipsychotic medication (olanzapine or risperidone) prescribed singularly increased to $21.35 \% .{ }^{17-19}$
The present study observed that in the olanzapine group $64 \%$ of the studied patients had weight gain whereas in the risperidone group only $20.8 \%$ reported weight gain. Statistically this was significant ( $p<0.001)$. Thus, it was observed that olanzapine has a higher probability to cause weight gain as compared to risperidone. This observation is in agreement with the results of the study by Simpson MM et al, which concluded that there is a more significant association between olanzapine and weight gain as compared to clozapine or risperidone..$^{20}$

In the present study in less than 139 serum sodium level categories, olanzapine showed significant association between olanzapine and increase in waist circumference $\left(\mathrm{x}^{2}=4.43, \mathrm{p}<0.05\right)$. Similarly, in more than 139 serum sodium level categories, olanzapine also showed significant association between olanzapine and increase in waist circumference $\left(x^{2}=25.34, p<0.05\right)$. The results revealed that olanzapine was primarily responsible for increase in waist circumference over risperidone. Though there was no impact of sodium status on the same $\left(x^{2}=0.0148, p>0.05\right)$. This finding also is in corroboration with the randomized double blind study by Ader $\mathrm{M}$ et al, conducted over a period of six months which confirmed increase in waist circumference after treatment with olanzapine using objective parameters (abdominal CT) to quantify visceral adiposity. ${ }^{21}$

The limitations of the present study were that author could only study younger adults within this study sample as $88.4 \%$ patients studied were between $20-49$ years. 
Younger patients are often healthier and may be less susceptible to develop drug induced hyponatremia. Secondly, author's follow up was done after two weeks at which point the study ended and long term risk of hyponatremia due to the therapeutic use of atypical antipsychotic medications could not be examined.

\section{CONCLUSION}

Based on the observations of the present study, it can be concluded that olanzapine was primarily responsible for weight gain and increase in waist circumference over risperidone. These gross metabolic parameters were not influenced by hyponatremia.

\section{ACKNOWLEDGEMENTS}

Authors would like to thank Department of Psychiatry and Dr. OP Raichandani for their support during study.

Funding: No funding sources

Conflict of interest: None declared

Ethical approval: The study was approved by the Institutional Ethics Committee

\section{REFERENCES}

1. Charlson FJ, Ferrari AJ, Santomauro DF, Diminic S, Stockings E, Scott JG, et al. Global epidemiology and burden of schizophrenia: findings from the global burden of disease study 2016. Schizophrenia Bull. 2018;44(6):1195-203.

2. Gandhi S, McArthur E, Reiss JP, Mamdani MM, Hackam DG, Weir MA, et al. Atypical antipsychotic medications and hyponatremia in older adults: a population-based cohort study. Can J Kidney Heal Dis. 2016;3(1):21.

3. Collins A, Anderson J. SIADH induced by two atypical antipsychotics. Int $\mathrm{J}$ Geriatric Psychiatry. 2000;15(3):282-3.

4. Meulendijks D, Mannesse CK, Jansen PA, Marum RJ, Egberts TC. Antipsychotic-Induced Hyponatraemia. Drug Safety. 2010;33(2):101-14.

5. Whitten JR, Ruehter VL, Pharm BS. Risperidone and hyponatremia: a case report. Ann Clin Psychiatry. 1997;9(3):181-3.

6. Dudeja SJ, McCormick M, Dudeja RK. Olanzapine induced hyponatraemia. Ulster Med J. 2010;79(2):104.

7. Bakhla AK, Guria RT, Kumar A. A suspected case of olanzapine induced hyponatremia. Ind J Pharmacol. 2014;46(4):441.

8. Ranga GS, Tomar LR, Narang S, Tripathi P, Jirwal OP. Risperidone causing hyponatremia. J Acute Med. 2014;4(3):133-4.
9. Lareb. The Netherlands Pharmacovigilance Centre. Olanzapine and hyponatraemia. Holland: Hertogenbosch, 2006. Available at: https://databankws.lareb.nl/Downloads/kwb_2006_1 _olanz.pdf. Accessed 03 Aug 2013.

10. Foreyt J, Goodrick K. The ultimate triumph of obesity. Lancet. 1995;346(8968):134-5.

11. Kalucy RS. Drug-induced weight gain. Drugs. 1980;19(4):268-78.

12. Pijl H, Meinders AE. Bodyweight change as an adverse effect of drug treatment. Drug Safety. 1996;14(5):329-42.

13. Umbricht D, Kane JM. Medical complications of new antipsychotic drugs. Schizophrenia Bull. 1996;22(3):475-83.

14. Stanton JM. Weight gain associated with neuroleptic medication: a review. Schizophrenia Bull. 1995;21(3):463-72.

15. Mannesse CK, Puijenbroek EP, Jansen PA, Marum RJ, Souverein PC, Egberts TC. Hyponatraemia as an adverse drug reaction of antipsychotic drugs. Drug Safety. 2010;33(7):569-78.

16. Orsolini L, Tomasetti C, Valchera A, Vecchiotti R, Matarazzo I, Vellante F, et al. An update of safety of clinically used atypical antipsychotics. Expert Opinion Drug Safety. 2016;15(10):1329-47.

17. Kumar S, Berl T. Sodium. Lancet. 1998;352(9123):220-8.

18. Wald R, Jaber BL, Price LL, Upadhyay A, Madias NE. Impact of hospital-associated hyponatremia on selected outcomes. Arch Int Med. 2010;170(3):294302.

19. Wannamethee SG, Shaper AG, Lennon L, Papacosta O, Whincup P. Mild hyponatremia, hypernatremia and incident cardiovascular disease and mortality in older men: a population-based cohort study. Nutrition Metab Cardiovascular Dis. 2016;26(1):12-9.

20. Simpson MM, Goetz RR, Devlin MJ, Goetz SA, Walsh BT. Weight gain and antipsychotic medication: differences between antipsychotic-free and treatment periods. J Clin Psychiatry. 2001;62(9):694-700.

21. Ader M, Garvey WT, Phillips LS, Nemeroff CB, Gharabawi G, Mahmoud R, et al. Ethnic heterogeneity in glucoregulatory function during treatment with atypical antipsychotics in patients with schizophrenia. J Psychiatric Res. 2008;42(13):1076-85.

Cite this article as: Daryani KK, Sethi G, Sethi S. Relation between hyponatremia and alteration in gross metabolic parameters after atypical antipsychotic therapy. Int J Basic Clin Pharmacol 2019;8:856-9. 